\title{
KOKEMUSTEN TUOTTAMISESTA
}

Kun Yhdysvaltojen presidentti Donald Trump perusteettomasti syyttää The New York Timesin juttuja valeuutisiksi ja lehden toimittajia valetoimittajiksi, hän vetoaa uskollisten kannattajiensa ja someseuraajiensa tunteisiin (ks. Görman 2018). Samalla Trump ilmeisen tarkoitushakuisesti voimistaa käynnissä olevaa yhteiskunnallista polarisoitumista - etenkin Yhdysvalloissa. Toisessa suurvallassa Venäjällä Vladimir Putinin hallinto on ottanut valtaansa oikeuslaitoksen, talouden ja ennen muuta median. Valtamedian sisällöt ovat Kremliä suosivia, ja sosiaalisen median kanavilla liikkuu ammattimaisia trollaajia, jotka toimivat Putinin "piikkiin" (ks. Kolamo tulossa). Niin Trumpin kuin Putinin hallinnon puhetavoissa on kyse kokemusten tuottamisesta tavalla, jossa pyrkimyksenä on vahvistaa oman poliittisen ryhmän suosiota ja yhteiskunnallista asemaa.

Populistipoliitikkojen on todettu vähät välittävän tosiasioista ja perustavan näkemyksensä mielipiteisiin ja "omiin kokemuksiinsa". Tällöin kannattajajoukkojen yhteisötunnetta usein vahvistetaan käyttämällä hyväksi ennakkoluuloja ja mututietoa. Toisaalta kokemusta voidaan myös tutkia huolella laadittujen kyselyjen, haastattelujen ja etnografioiden avulla. Näin voidaan löytää käyttökelpoista tietoa vaikkapa koululaisten koetusta terveydestä tai innostuneisuudesta ottaa kantaa päivänpolttaviin yhteiskunnallisiin ongelmiin. Kokemus onkin hyvin moniulotteinen käsite. Se kytkeytyy tieteenfilosofisesti ja käsitehistoriallisesti monentyyppisiin keskusteluihin - puhumattakaan sanan arkiymmärryksestä ja monista erilaisista käyttötavoista ja -yhteyksistä. (Toikkanen \& Virtanen 2018; Backman 2018.) Kokemuksen käsitteen tieteenfilosofisten ja -historiallisten ja arkiymmärrykseen ankkuroituneiden merkityssisältöjen sijaan tämän Lähikuvan teemanumeron painopiste on kokemusten tuottamisessa.

Tuottamisen idea johtaa ajattelemaan kokemuksen välittyneisyyttä. Thmisen aistit virittyvät esitysten, kuten taiteen tai median kuvien, vaikutuksesta. Esitysten välittämät niin kerronnalliset, esteettiset, tiedolliset, tunteelliset kuin muutkin aspektit raamittavat sitä, mitkä asiat ylimalkaan nousevat yhteiskunnassa puheeksi, ja miten asioista eri foorumeilla puhutaan. Kyse on siis esitysten agenda- ja kehystysvallasta. Iso osa etenkään taiteilijoiden töistä ei saa koskaan ansaitsemaansa näkyvyyttä ja julkisuutta. Eivätkä niiden sisältämät näkökulmat siksi nouse laajan yhteiskunnallisen keskustelun kohteeksi.

Jakelujärjestelmien hallinnoijilla ja muilla valtaapitävillä on valta jakaa esityksiä eteenpäin vastaanottajien eli kulttuurituotteiden kuluttajien koettavaksi. Tuotteiden omistajien ja jakelijoiden ryhmä ei ole kuitenkaan näkökulmissaan 
täysin yhtenäinen, kuten ei ole vastaanottajienkaan joukko. Tuotannosta ja kulutuksesta puhuttaessa nykyisessä digitaalisessa mediamaisemassa on otettava huomioon prosumerit, vaikka tuottajakuluttajia ja tee se itse -kulttuuria teemanumerossa ei varsinaisesti käsitelläkään. Esitykset ovat tietyllä tavalla arvolatautuneita ja täten välittyneisyyden ohella ne ovat vallan koskettamia. Etenkin kun kyse on totalitaristisista valtioista (vaikkapa Pohjois-Koreasta), tulkitsemme helposti minkä tahansa esityksen valtanäkökulmasta. Ideologiateoreetikko Louis Althusseria (1984) mukaillen tietyntyyppiset esitykset "kutsuvat" yhteisöjä valitsemaan puolensa. Tästä lähtökohdasta näyttäisivät olevan tietoisia myös edellä mainitut valtionpäämiehet.

Kokemusten tuottamisessa on siis kyse ainakin välittyneisyydestä, vallasta ja vas(tus)tuksesta, vastaanoton käytännöistä ja yhteisöjen muodostamisesta. Teemanumerossa puhutaan myös tunteista ja kokemuksen kehollisuudesta, esitysten kertovuudesta sekä tapahtumatiloista, joissa intensiivinen yhteisöllinen kokemus tiivistyy.

\section{Totalitarismi ja propagandistiset tapahtumatilat}

Siinä missä Trumpin mediapuheet kannustavat vastakkainasetteluihin, Venäjän nykyhallinnon vallankäyttöä voi monin osin kutsua totalitaristiseksi. Klassikkoesimerkki totalitarismista on kuitenkin natsi-Saksa (Arendt 1976). Hitlerin Saksassa koko yhteiskuntajärjestelmä - media, liikenne, teollisuus, kansalaiset - oli rakennettu palvelemaan kansallissosialistista regiimiä ja sen manifestoimia arvoja.

Natsipropagandassa tosiasioiden tilalla loistivat ideologiset kuvitelmat. "Uuden uljaan Saksan" retoriikka ammensi pitkälti antiikin Kreikan ja Rooman kulttuuriperinnöstä. Natsit muuttivat ympäristön vastaamaan omia tarkoitusperiään ja pyrkivät kiinnittämään ihmisten huomion tähän propagandistiseen kuvaan yhteiskunta- ja arkielämän kaikilla lohkoilla. Samalla natsit kasvattivat kokonaisen sukupolven uskomaan arjalaisen herrarodun ylivertaisuuteen. Natsismin ihanneihminen oli kuuliainen kansalainen, jolle paitsi faktan ja fiktion myös oikean ja väärän välisellä erolla ei ollut enää mitään väliä.

Nykyisen radikaalioikeiston - ja "vaihtoehtoisten totuuksien ja faktojen" vietäväksi antautuneen sekä johtajiensa käskyjä sokeasti toteuttavan rasistisen ihmistyypin - nousua seuratessa on paikallaan muistuttaa natsien propagandan toimintalogiikasta (ks. myös Jokisalo 2016). Teemanumerossa tätä tehtävää suorittaa Sami Kolamon ja Jani Vuolteenahon artikkeli "Natsit kansojen välisen ystävyyden asialla". Artikkelissa keskitytään vuoden 1936 Berliinin olympialaisten organisointiin ja esillepanoon. Berliinin olympialaiset olivat natsien esilletulojuhla globaalin median katseiden alla. Siksi Berliinistä ja erityisesti sen tapahtumatiloista tuli rakentaa ihmisten tunteisiin vetoavia. Natsit halusivat tehdä vaikutuksen etenkin ulkomaalaisiin urheilijoihin ja toimittajiin sekä turisteihin. Natseilla oli käytössään aikansa huippumediateknologioita, joiden avulla sentit ja sekunnit sekä monentyyppiset tarinat välitettiin ihmisten kuultavaksi ja nähtäväksi. Natsit onnistuivat propagandatyössään, sillä Berliinin olympialaiset, kuten myös olympialaisista kertova Leni Riefenstahlin elokuva, keräsivät laajasti kehuja eri puolilla maapalloa.

Jos Berliinin olympialaisten spektaakkelimaisuus ja hyvä tunnelma ovat kiinnostaneet jälkipolvia, samaa voi sanoa natsi-Saksasta ylimalkaan. Tätä jatkuvaa ja samalla ajassa elävää kiinnostusta analysoi Kari Kallioniemen ja Kimi Kärjen katsaus "Populaarikulttuurin estetisoima ja normalisoima natsismi". 


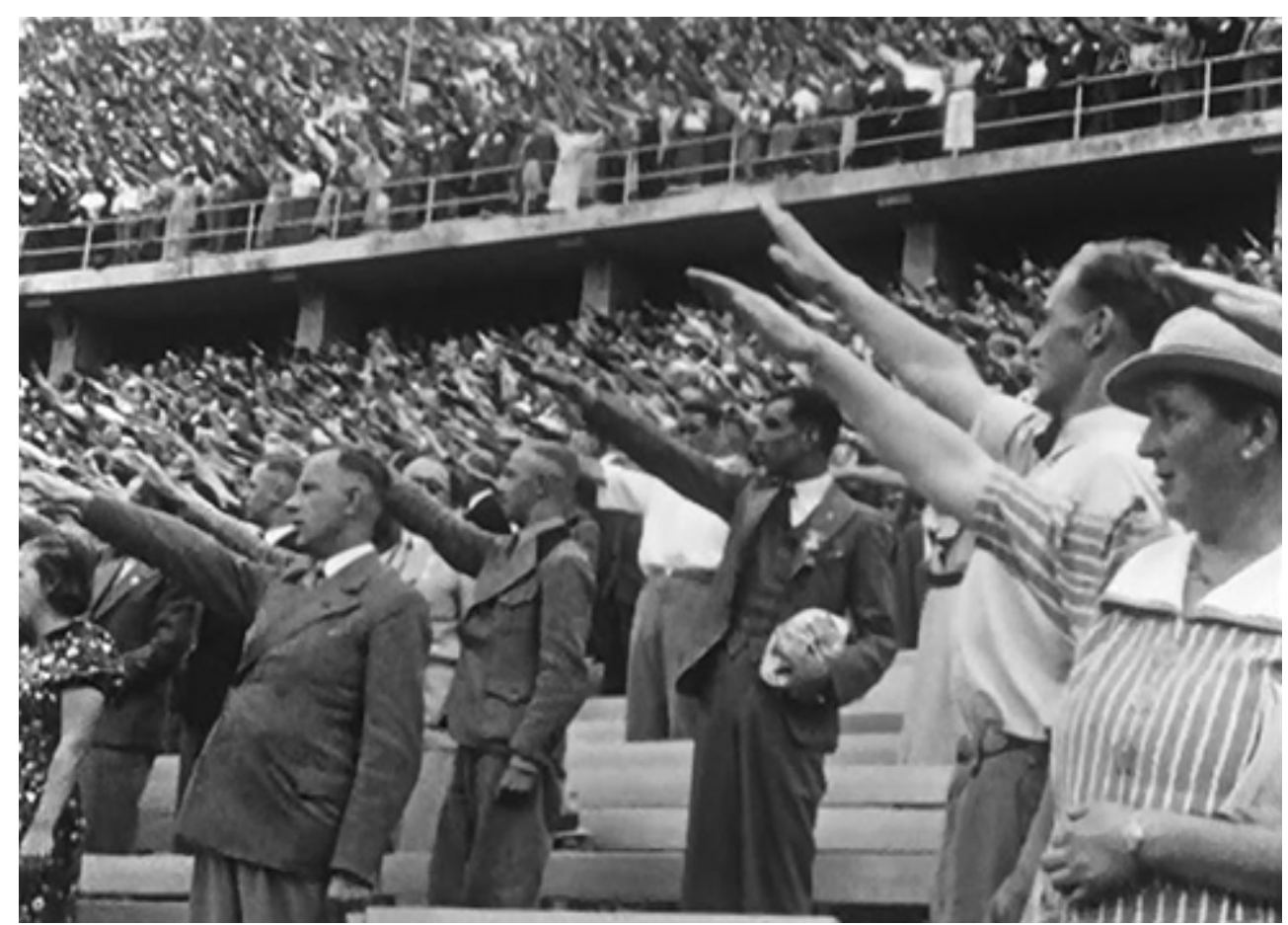

Kuva 1. Katsojat tekevät natsitervehdyksen Berliinin olympiastadionilla vuoden 1936 olympialaisten palkintojenjakoseremonian aikana. Lähde: kuvakaappaus Emanuel Hübnerin dokumenttielokuvasta (2011) Olympia 1936: Die Olympischen Spiele 1936 in Privaten Filmaufnahmen.

Kallioniemi ja Kärki kirjoittavat Gavriel D. Rosenfeldin näkemyksiä lainaten, että populaarikulttuurin teoksissa - elokuvissa, televisiosarjoissa, musiikkivideoissa, sarjakuvissa - on vähitellen siirrytty antifasistisista näkökulmista natsismin estetisoimiseen tavalla, joka on tuottanut jopa vähättelevää asennetta natsismia kohtaan. Kallioniemi ja Kärki toteavat ajatuksia herättävästi:"Japanissa SS-uniformuun pukeutuva roolipelaaja ei välttämättä tiedosta asunsa alkuperää, eikä itsestään ja kavereistaan Auschwitzissa selfieitä ottava nuori ymmärrä kunnioittaa holokaustin uhreja ja sen mittakaavaa ja käyttäytyy siksi kuin millä tahansa turistikohteella." Toisaalta he myös huomauttavat, että natsismin populaarikulttuurinen kuvasto on hyvin monisäikeinen ja siten avoin erilaisille tulkinnoille ja käyttötavoille. Kallioniemi ja Kärki korostavatkin kulttuurihistoriallisen kokonaistulkinnan tärkeyttä, sillä tämä voi auttaa ymmärtämään myös nykyistä poliittista myllerrystä suhteessa natsismin fasinaatioon.

\section{Taide ja vastaanoton ambivalenttisuus}

Taiteelle ei tulisi määritellä tarkasti rajattua tehtävää - etenkään hyötynäkökulmista. Taiteen kokeminen pakenee kielellisiä määrittely-yrityksiä. Siksi se liitetään usein mielihyvän, nautinnon, tunteen ja tuntumisen sekä kehollisen kokemisen kaltaisiin käsitteisiin. Toisinaan taidekokemukset voivat olla yksilöllisesti niin ravisuttelevia ja väkeviä, että ne saavat henkilön muuttamaan elämänsä suunnan. Käänteisellä tavalla taiteen yhteiskunnallisesta vaikutus- 
voimasta kertovat puolestaan kirjaroviot, sensuurit, boikotit ja taiteentekijöiden vankilatuomiot sekä kotiarestit.

Ehkäpä juuri ihmisiä joukoittain kiihottavien vaikutustensa vuoksi taide on ollut valtaapitävien määrittelyn kohteena. Kun valtiolliset instituutiot ovat jakaneet resursseja taiteentekijöille, "huonoksi" luokiteltu taide ja "vääräuskoisiksi" tulkitut taiteilijat ovat jääneet nuolemaan näppejään. Joitakin vuosia sitten perussuomalaiset linjasivat, että postmoderniin tekotaiteeseen ei tulisi Suomessa haaskata euroakaan. Populistiset taidepoliittiset linjaukset vaalien alla kertovat osaltaan odotuksista "hyvää" taidetta ja taiteentekijöiden esityksiä kohtaan.

Taideteokset ovat usein monitulkintaisia, eikä niitä siksi ole yksinkertaista luokitella tiettyyn kategoriaan - semminkin, kun tulkitsijoita, joita myös vastaanottajiksi voi kutsua, saattaa olla yksittäisellä teoksella Suomessakin satojatuhansia. Teemanumerossa taiteen vastaanoton ambivalenttisuutta avaa Mia Öhmanin artikkeli "Peili-elokuvan vastaanotto Suomessa". Öhman perehtyy neuvostoelokuvan yhden tunnetuimman ohjaajan Andrei Tarkovskin mestariteokseen, joka sai ristiriitojen sävyttämän vastaanoton. Elokuva valmistui vuonna 1974; Suomen elokuvateatterilevitykseen Peili pääsi vuonna 1978.

Elokuva ei täyttänyt Neuvostoliiton kommunistisen puolueen elokuvalle määrittelemiä ideologisia kriteerejä - tai pikemminkin paini omassa sarjassaan määrittelyjen ulkopuolella. Ulkomailla Tarkovskin elokuvista kuitenkin pidettiin: elokuvafriikkien keskuudessa hän oli eräänlainen kulttihahmo. Tarkovskin auteuristisesta taidekäsityksestä kertoo paljon hänen toteamuksensa: "Se, että katsojat ja kriitikot sataprosenttisesti ymmärtävät ja ovat samaa mieltä teoksesta, merkitsee teoksen muuttumista kulutustavaraksi, banaaliksi, taiteilijan ominaisuutta olla kaikkien silmissä miellyttävä ja harmiton [...] se on kuin vedellä laimennettua väljehtynyttä viiniä. Sellaiselta taiteelta aina puuttuu yksilöllinen voima." Vaikka Tarkovski halusi elokuvilleen katsojia niin kotimaassa kuin ulkomailla (mukaan lukien Suomessa), hän tuskin olisi suostunut Leonid Brežnevin hallinnoiman Neuvostoliiton taiteen vienninedistämisen mannekiiniksi. Sellainen hänestä kuitenkin tavallaan tuli. Neuvostoliitosta länteen siirtyneen elokuvakriitikko Valeri Golovskoin (Golovskoy \& Rimberg 1986) mukaan Tarkovskilla ei itsellään ollut kokonaiskäsitystä neuvostosysteemin sisäisestä tilanteesta, jossa hänen sallittiin tehdä elokuvia "vientiin", länsimaille suunnattuna osoituksena neuvostotaitelijoiden vapaudesta.

Tarkovskin Peilin tapauksessa Neuvostoliitossa toimijaosapuolina olivat kommunistisen puolueen keskuskomitean hallinnoima keskitetty elokuvatuotantosysteemi Goskino ja monopolistisessa asemassa oleva levittäjä, niin ikään puoluejohdon hallinnoima Sovexportfilm, jolla oli toimipisteitä yli 50:ssä maassa. Suomessa Sovexportfilmin alaisina toimivat neuvostoelokuvia myyvä ja vuokraava Kosmos-Filmi ja elokuvateatteri Capitol Mannerheimintiellä, yhteistyökumppaneinaan Suomi-Neuvostoliitto-Seura ja Suomen elokuvakerhojen liitto SEKL ja tapahtumien suojelijana jopa itse tasavallan presidentti. Suomi oli valistunut elokuvamaa, ja toimittajat ja elokuvaentusiastit kirjoittivat muustakin kuin Hollywoodin hiteistä, esimerkiksi ranskalaisesta uudesta aallosta ja venäläisestä taide-elokuvasta.

Öhmanin artikkelin rinnakkaistekstinä toimii Lauri Piispan katsaus "Stalinin ajan elokuvan paluu". Tarkovskin aikanakin Neuvostoliiton elokuvajohdossa ja ennen kaikkea Sovexportfilmin edustustehtävissä kotimaan ulkopuolella toimi joitakin todellisia elokuvan rakastajia, jotka ymmärsivät ja osasivat arvostaa muutakin kuin yhteiskunnallisesti etabloitua isänmaallista elokuvaa. Jopa Stalinin valtakauden aikana (1928-1953) tuotettiin ja levitettiin 
esteettis-ilmaisullisesti kiinnostavia, taiteellisesti korkeatasoisia elokuvia - ei siis pelkkää sosialistisen realismin määreen alla kulkevaa bulkkipropagandaa, kuten joskus on yleistetty. Arkaluonteisiin yhteiskunnallisiin asioihin, kuten vankileireihin ja joukkomurhiin, elokuvissa ei voinut viitata. Elokuvan tärkeä tehtävä oli viihdyttää ja kasvattaa neuvostokansaa. Elokuvien ja usein niiden tekijöidenkin kohtalon määräsi valtakunnan ylin asiantuntija. Tapa eli vielä niin kutsutun pysähtyneisyyden ajan elokuvahallinnossa - elokuvan kohtalon saattoi edelleen sanella yhden henkilön mielipide.

\section{Mediakokemuksen kehollisuus}

Mediafilosofi Marshall McLuhanin (1964) lentävä lausahdus kuului: "Väline on viesti". Yhteiskunnan digitalisoitumisen myötä tästä ajatuksesta on tullut entistä kiinnostavampi. Mitä enemmän tekoäly algoritmeineen ja ihminen aistillis-ruumiillisine ominaisuuksineen yhdistyvät, sitä tärkeämpiä ovat kysymykset median teknologisesta merkityksestä. Erityisesti virtuaalitodellisuuksien tarkastelussa teknologialla on väliä (ks. Huhtamo 1995). VR-laitteiden valmistajat pyrkivät siihen, että laitteet istuvat ruumiiseen (päähän, vartaloon, käsiin) mahdollisimman sulavasti eli ne ovat tarjoumiltaan vietteleviä. Virtuaalitodellisuus teknologiana tarjoaa toisaalta uusia mahdollisuuksia tarinankerronnalle. Kertovina ja kokemuksiin vaikuttavina immersiivisinä esityksinä virtuaalitodellisuuden maailmat pyrkivät häivyttämään tunteen teknologiasta kokijan ja maailman "välissä" olevana sfäärinä. Näihin asioihin kiinnittää huomiota Maria Laakson artikkeli "Helsinki kuin Aleppo".

Laakso käyttää esimerkkinä vuonna 2017 valmistunutta Ylen virtuaaliteosta, jossa Helsingin Kolmen sepän patsaan ympäristö on pirstoutunut pommitusten jäljiltä. Laakso erittelee virtuaalikokemuksen immersiivisyyttä, kertovuutta ja kulttuurisia konteksteja. Viimeksi mainittuja ovat lähinnä kaupunkiapokalypsien kirjallinen ja elokuvallinen perinne sekä uutiskuvat tuhoutuneista kaupungeista. Laakson analyysi osoittaa, että verrattuna varhaisempiin visuaalisen ja audiovisuaalisen taiteen lajeihin virtuaalitodellisuuden immersiivisyys on voimakkaampi erityisesti kehon kokemuksen tasolla.

Laakson tulkinnassa kokemuksellisuus sijoittuu teoksen ja vastaanottajan välille, mutta palautuu niihin retorisiin keinoihin, joiden avulla teos pyrkii vaikuttamaan vastaanottajaansa. Kokemuksellisuuden kannalta Ylen virtuaaliteoksen kerrottavuudessa on kuitenkin puutteita. Siinä ei ole lainkaan henkilöhahmoja. Tämän puutteen vuoksi virtuaaliteos sisältää erillisen reaktiovideon, jossa tunnetut suomalaiset kuvailevat sitä, miltä teos heistä tuntuu. Parhaimmillaan kyseisten kaltaisten virtuaaliteosten - joiden avulla täällä (Suomessa) voi kuvitella, millaisena siellä (sodan runtelemassa maassa) arki näyttäytyy - ansiot eivät ole vain shokkiefekteissä, vaan niiden avulla on mahdollista kehittää empaattisuutta toisaalla eläviä ihmisiä kohtaan.

\section{Yksittäistapausten yleinen merkitys}

Huolimatta siitä, että tämän Totalitarismi, taide, kokemus -teemanumeron artikkeleissa ja katsauksissa valotetaan vain kapeita kaistaleita kokemuksen tutkimuksen laaja-alaiselta kentältä, teksteissä tartutaan ajankohtaisesti tärkeisiin teemoihin ja käsitteisiin. Näitä ovat muiden muassa median käsittäminen esityskanavan ohella teknologiana, tekstien kertovuus ja vaikutus kokemuk- 
siin sekä kehon tunnerekistereihin, medianäkyvyyden merkitys valtiopropagandassa (tai nykyisin paikkabrändäyksessä), tuotannon ja kulutuksen tai vastaanoton väliset merkityskamppailut, kaupunki- ja mediatilojen toisiinsa kietoutuminen tapahtumien tuottamisessa ja populaarikulttuurin esitysten lumo sekä toisto ja kierrätys. Toivomme, että teemanumeron artikkelit toimivat pontimena uusien ja innovatiivisten teorioiden ja tutkimusavausten kehittelyille.

Maaliskuussa 2019

\section{Sami Kolamo, Jani Vuolteenaho ja Mia Öhman}

\section{Lähteet}

Althusser, Louis (1984) Ideologiset valtiokoneistot. Helsinki: Kansankulttuuri.

Arendt, Hannah (1976) The Origins of Totalitarianism. New York: Harcourt Brace Jovanovich.

Backman, Jussi (2018) Äärellisyyden kohtaaminen: kokemuksen filosofista käsitehistoriaa. Teoksessa Toikkanen, Jarkko \& Virtanen, Ira (toim.) Kokemuksen tutkimus VI. Kokemuksen käsite ja käyttö. Rovaniemi: Lapland University Press, 25-40.

Golovskoy, Val[eriy] S. \& Rimberg, John (1986) Behind the Soviet Screen. The Motion-Picture Industry in the USSR 1972-1982. Michigan: Ann Arbor, Ardis.

Görman, Petri (2018) Trump syyttää taas New York Timesia valeuutisesta. Ye 20.8.2018. <https:// yle.fi/uutiset/3-10360308>.

Jokisalo, Jouko (2016) Euroopan radikaalioikeisto. Helsinki: Into.

Huhtamo, Erkki (1995) Virtuaalisuuden arkeologia - virtuaalimatkailijan uusi käsikirja. Rovaniemi: Lapin yliopiston taiteiden tiedekunta.

Kolamo, Sami (tulossa) Valtiopropagandan paluu - Venäjän jalkapallon MM-kisat 2018 pehmeän vallankäytön näyttämönä. Idäntutkimus 1/2019.

McLuhan, Marshall (1964) Understanding Media: The Extensions of Man. London: Signet.

Toikkanen, Jarkko \& Virtanen, Ira (2018) (toim.) Kokemuksen tutkimus VI. Kokemuksen käsite ja käyttö. Rovaniemi: Lapland University Press. 